\title{
Short-term Occurrence and Rapid Growth of Spanish mackerel Larvae in the Central Waters of the Seto Inland Sea, Japan
}

\author{
Jun Shoji, ${ }^{* 1}$ Tsutomu Maehara, ${ }^{* 2, \dagger}$ and Masaru Tanaka ${ }^{* 1}$ \\ ${ }^{*}$ Division of Applied Biosciences, Graduate School of Agriculture, Kyoto University, \\ Kitashirakawa, Kyoto 606-8502, Japan \\ ${ }^{*}$ Toyo Branch, Ehime Prefecture Chuyo Fisheries Experimental Station, \\ Kawarazu, Toyo, Ehime 799-1303, Japan
}

(Received June 24, 1998)

To investigate the early life history of Japanese Spanish mackerel Scomberomorus niphonius in the Seto Inland Sea, abundance, occurrence, feeding habits, and growth of larvae were examined from wild specimens collected in Hiuchi-nada in 1995 and 1996. In addition, Japanese Spanish mackerel were reared in the laboratory to determine the rate of otolith microstructual increment formation during early stages.

Japanese Spanish mackerel in the central waters of the Seto Inland Sea appear to have evolved a reproductive strategy of short-term spawning timed to correspond to the seasonal-peak abundance of their prey. Japanese Spanish mackerel laevae were almost exclusively piscivorous and their most important prey was Clupeiformes larvae with slender body form. Occurrence of Japanese Spanish mackerel eggs and larvae was restricted with a peak abundance in late May to early June, corresponding with a peak abundance of Clupeiformes larvae. Age estimation for 70 wild larvae and early juveniles revealed a mean growth rate of $1.03 \mathrm{~mm} /$ day between 4 and 20 days after hatching, which appears to be markedly higher than those from most of coastal marine fishes.

Key words: Spanish mackerel, larvae, occurrence, piscivory, otolith increment, growth, the Seto Inland Sea, early life strategy

Scombrid fish are generally considered to have survival strategies in early life stages characterized by piscivorous habits and rapid growth. ${ }^{1,2)}$ Especially high growth potential was observed in early life stages of Scomberomorus ${ }^{3-7)}$ and it could relate to precocious development of their digestive system and piscivorous habits from first feeding stage ${ }^{8)}$ Studies on the early growth and feeding habits of Scomberomorus have been done in Australian waters, ${ }^{9}$ off the Atlantic coast in U. S., and Gulf of Mexico..$^{5-7,10,11)}$ In the Seto Inland Sea, the spawning ground of Japanese Spanish mackerel Scomberomorus niphonius, most of previous biological studies have focused on biology of adult fish, ${ }^{12-19)}$ although preliminary information has been reported on distribution ${ }^{20)}$ and food habits ${ }^{21)}$ of the larvae.

$\mathrm{Kishida}^{22}$ reported that the larval survival rate of Japanese Spanish mackerel varied between years and that year-class strength seemed to be determined during the larval period. In order to clarify the recruitment mechanism of this species, this study examined occurrence, food habits, and growth in early stages of Japanese Spanish mackerel in the central waters of the Seto Inland Sea, major spawning area in recent years. ${ }^{20)}$

\section{Materials and Methods}

\section{Field Sampling}

Sampling was conducted two to three times per month,
March to June 1995 and April to June 1996, in Hiuchinada, the central waters of the Seto Inland Sea (Fig. 1) by the R/V Hiuchi $(4.9 \mathrm{t})$ and R/V Yuri $(4.9 \mathrm{t})$ of Ehime Prefecture Chuyo Fisheries Experimental Station. Tenminute surface (only in 1996) and mid-layer tows with a conical larva-net (mouth diameter $1.3 \mathrm{~m}$, mesh aperture $1.0 \mathrm{~mm}$ ) were made to collect Japanese Spanish mackerel

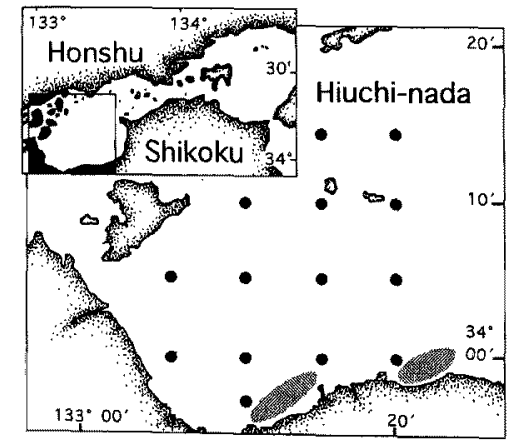

Fig. 1. Map of Hiuchi-nada, the central waters of the Seto Inland Sea, showing the sampling area where Japanese Spanish mackerel eggs, larvae, and early juveniles were collected in 1995 and 1996.

Solid circles and shaded areas indicate sampling stations where horizontal and vertical hauls of larva nets were conducted and sampling areas where a boat seine fishery was operated, respectively.

\footnotetext{
$\dagger$ Present address: Agricultural Administration and Fisheries Division, Uwajima Regional Office, Ehime Prefecture, Tenjin, Uwajima, Ehime 798-0036, Japan.
} 
eggs and larvae, respectively. Vertical hauls with a conical plankton net (mouth diameter $0.6 \mathrm{~m}$, mesh aperture 0.315 $\mathrm{mm}$ ) were also made at each station. Ichthyoplankton samples were preserved in 10\% formalin and Japanese Spanish mackerel larvae were preserved in $90 \%$ ethanol within 24 hours after $10 \%$ formalin fixation. The volumes of seawater filtered by the nets were measured by a flowmeter mounted on the mouth of the net, and the number of ichthyoplankton by horizontal and vertical hauls were converted to catch per $1000 \mathrm{~m}^{3}$ and $1 \mathrm{~m}^{2}$, respectively. Stomach-contents composition of 274 Japanese Spanish mackerel larvae ranging from 3.9 to $11.9 \mathrm{~mm} \mathrm{SL}$ were examined and body heights (BH) of preyed animals in stomachs were measured when possible.

In addition, advanced-stage larvae and early juveniles of Japanese Spanish mackerel were collected in June and July, 1995 and 1996 from catches by the "Patchi-ami", a boat seine fishery which operates primarily to fish Japanese anchovy Engraulis japonicus larvae and juveniles in southern areas of Hiuchi-nada. Those larvae and juveniles, ranging between 9.5 and $23.1 \mathrm{~mm} \mathrm{SL}$, were fixed and preserved by the same manner as the specimens collected by the larva-net sampling.

\section{Rearing Experiments}

A rearing experiment was conducted to validate daily formation of otolith increments of Japanese Spanish mackerel larvae and early juveniles. Artificial fertilizations were carried out with 2 males and 3 females captured by drift gill net in Harima-nada, the eastern Seto Inland Sea on May 16, 1990. Eggs were transported to Kyoto University Fisheries Research Station, Maizuru, Kyoto and maintained in a $0.5 \mathrm{~m}^{3}$ tank. Water temperature was $17.6-23.8^{\circ} \mathrm{C}$ and light condition was natural during the rearing experiment. Larvae of red sea bream Pagrus major and Japanese flounder Paralichthys olivaceus were fed from 3 days after hatching and frozen anchovy larvae from 17 days after hatching. Twenty fish were sampled from the tank on day 17, 19, and 21 and were preserved in $90 \%$ ethanol.

\section{Otolith Increment Counting}

Right-side sagittal otoliths of 70 wild and 60 reared fish were removed under a dissecting microscope, and otolith increments were counted under a compound microscope with a video monitor.

\section{Results}

\section{Seasonal Occurrence of Japanese Spanish Mackerel Eggs and Larvae}

Seasonal variations in density $\left(N / 1000 \mathrm{~m}^{3}\right)$ of Japanese Spanish mackerel eggs and larvae obtained by the larvanet horizontal hauls in Hiuchi-nada 1995 and 1996 are shown in Fig. 2. Eggs began to appear in mid May and the density increased to more than $1000 / 1000 \mathrm{~m}^{3}$ in late May when it reached a peak, then decreased to less than 300/ $1000 \mathrm{~m}^{3}$ in early June. The seasonal change of occurrence of the larvae was very similar with that of the eggs, although the peak occurrence in larvae was about 10 days behind that of the eggs.

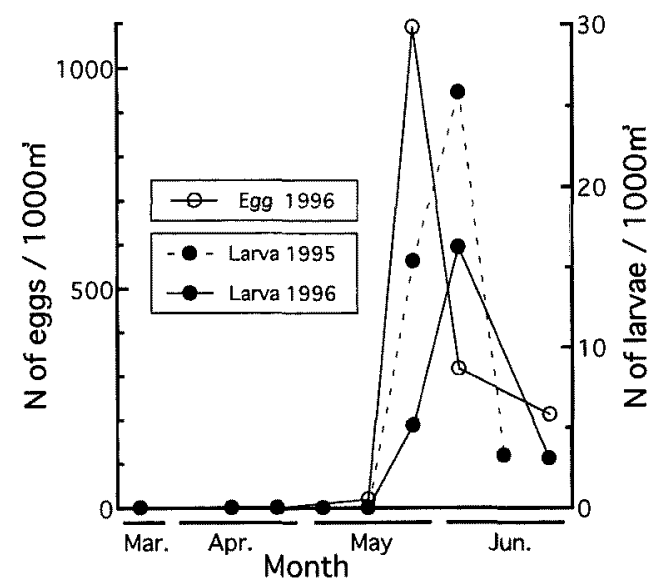

Fig. 2. Seasonal variations of mean density (number $/ 1000 \mathrm{~m}^{3}$ ) of Japanese Spanish mackerel eggs and larvae in Hiuchi-nada, in 1995 and 1996.

The density of eggs and larvae were obtained from the horizontal hauls in the surface (in 1996) and in the middle layer (in 1995 and 1996), respectively.

Table 1. Feeding incidence and stomach contents composition of Japanese Spanish mackerel larvae in terms of number of food items

\begin{tabular}{lll}
\hline & 1995 & 1996 \\
\hline N of larvae examined & 121 & 153 \\
N of larvae with food & 95 & 127 \\
Feeding incidence (\%) & 78.5 & 83.0 \\
Size range (mm SL) & $4.0-10.7$ & $3.9-11.9$ \\
\hline Contents & $\mathrm{N}(\%)$ & $\mathrm{N}(\%)$ \\
\cline { 2 - 3 } Invertebrate egg & $1(1.0)$ & $0(0)$ \\
Copepoda & $3(2.9)$ & $0(0)$ \\
Sardinops melanostictus & $8(7.8)$ & $7(5.1)$ \\
Konosirus punctatus & $5(4.9)$ & $4(2.9)$ \\
unidentified Clupeidae & $5(4.9)$ & $10(7.2)$ \\
Engraulis japonicus & $5(4.9)$ & $1(0.7)$ \\
unidentified Clupeiformes & $28(27.5)$ & $67(48.6)$ \\
Liza & $2(2.0)$ & $1(0.7)$ \\
Luciogobius & $3(2.9)$ & $0(0)$ \\
unidentified Gobiidae & $20(19.6)$ & $5(3.6)$ \\
unidentified fish & $22(21.6)$ & $16(11.6)$ \\
unidentified & $0(0)$ & $27(19.6)$ \\
Total & 102 & 138 \\
\hline
\end{tabular}

\section{Stomach-contents Composition}

Average feeding incidence of Japanese Spanish mackerel larvae was $78.5 \%$ in 1995 and $83.0 \%$ in 1996 (Table 1). Most of food items were fish larvae although a negligible number of invertebrate plankton were observed. Clupeiformes larvae including Japanese sardine Sardinops melanostictus, gizzard shad Konosirus punctatus, and Japanese anchovy occupied $63.2 \%$ and $93.7 \%$ of identified food items in 1995 and 1996, respectively. The other two major groups of preyed fish larvae found in the stomachs were Liza (Mugilidae) and Gobiidae.

\section{Seasonal Occurrence of Ichthyoplankton}

Seasonal variations in density of fish larvae obtained 


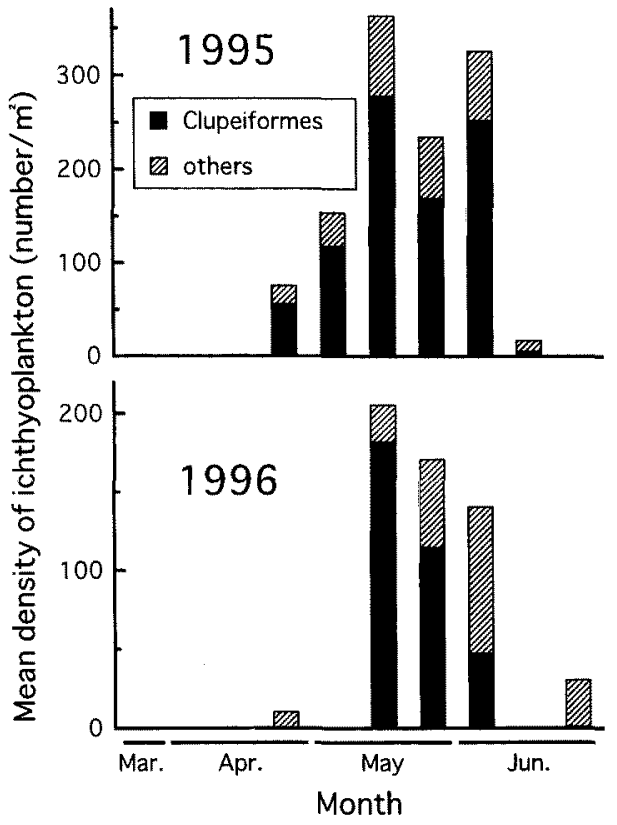

Fig. 3. Seasonal variations of mean density (number $/ \mathrm{m}^{2}$ ) of ichthyoplankton obtained from the vertical hauls in Hiuchi-nada in 1995 and 1996.

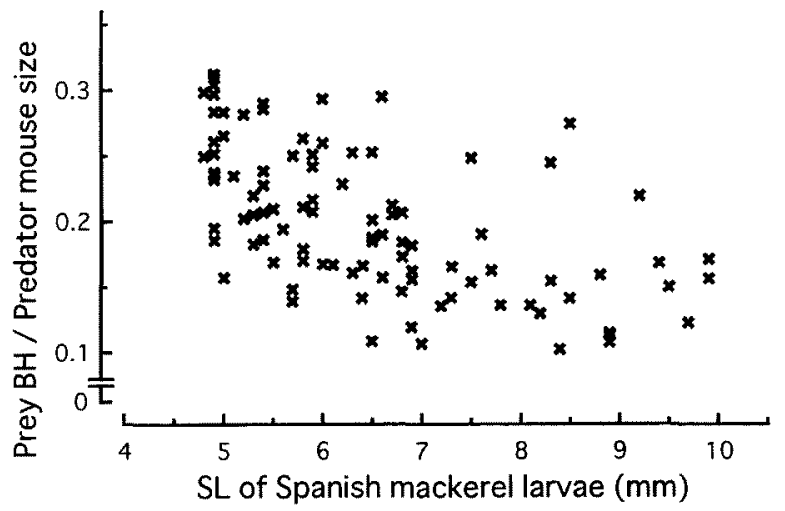

Fig. 4. Ratio of body height (BH) of larval fish prey in stomachs of Japanese Spanish mackerel larvae and mouth diameter (MD).

from vertical plankton net hauls in Hiuchi-nada in 1995 and 1996 are shown in Fig. 3. Larval densities were low in both early and late sampling periods while they were high only between mid May and early June in both 1995 and 1996. The ichthyoplankton predominantly consisted of Clupeiformes, Gobiidae, Carangidae, Callionymidae, and Scomber. Among these taxa, Clupeiformes larvae were dominant during the peak-abundance period.

Relationship Between Prey Size and Mouth Size of Japanese Spanish Mackerel Larvae

Generally prey size is closely correlated with mouth size of larval fish and ability to capture the prey ${ }^{2)}$ Ratios of body height $(\mathrm{BH})$ of preyed larvae to mouth diameter (MD) of Japanese Spanish mackerel larvae are shown in Fig. 4. MD were calculated by the following equation ac-

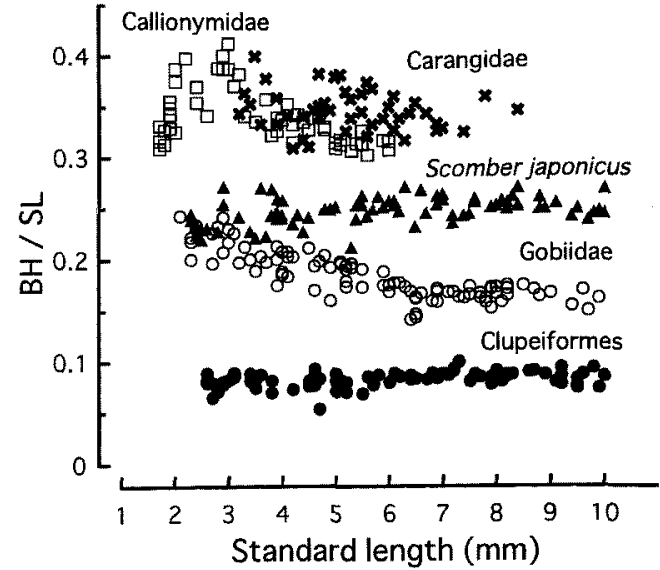

Fig. 5. Ratio of body height (BH) to standard length (SL) of 5 most dominant potential prey groups appeared in the water column.

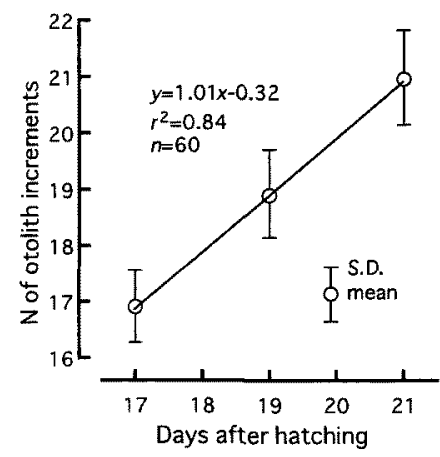

Fig. 6. Relationship between the number of increments in sagittal otolith and the number of days after hatching of laboratory-reared Japanese Spanish mackerel.

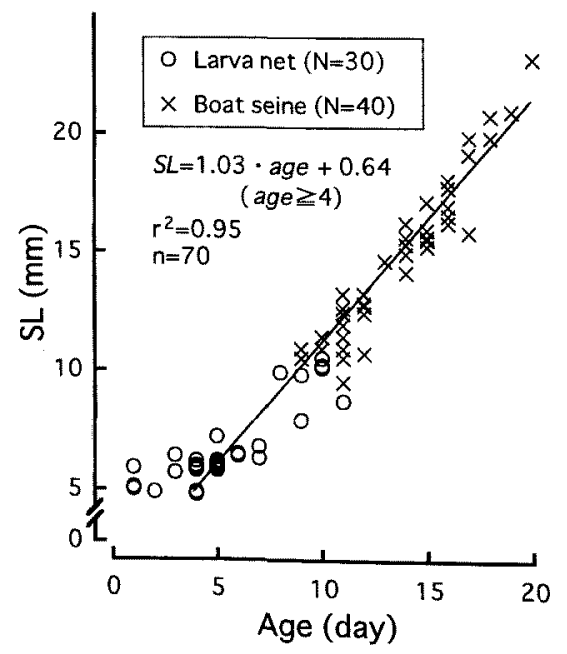

Fig. 7. Relationship between standard length (SL) and estimated age in days of wild Japanese Spanish mackerel larvae and early juveniles collected in Hiuchi-nada. 
cording to Shirota. ${ }^{23)}$

$$
M D=\sqrt{2} \cdot U J L \quad \text { (UJL: upper jaw length) }
$$

The ratios seemed to decrease as larvae developed, but generally were between 0.1 and 0.3 . Figure 5 shows ratios of $\mathrm{BH}$ to standard length (SL) of 5 dominant potential prey groups that occurred in water: Clupeiformes, Carangidae, chub mackerel Scomber japonicus, Gobiidae, and Callionymidae. BH/SL of Clupeiformes larvae was smallest and followed by that of Gobiidae, which had a $\mathrm{BH} / \mathrm{SL}$ ratio approximately twice that of Clupeiformes.

Growth of Japanese Spanish Mackerel in Early Life Stages

Otolith increments of Japanese Spanish mackerel coincided in number to age in days during the rearing experiment (Fig. 6). The age of wild larvae and early juveniles ranging between 4.8 and $23.1 \mathrm{~mm}$ in SL was estimated to be between 1 and 19 days after hatching based on the number of otolith increments. Growth during the yolk-sac stage was very slow or negligible until 4 days old while the growth after yolk absorption is notable. Relationship between standard length $(L, \mathrm{~mm})$ and estimated age $(D$, days) for the wild fish ( $D \geqq 4:$ after yolk absorption) was expressed by the following linear equation (Fig. 7).

$$
L=1.03 D+0.64 \quad\left(r^{2}=0.95\right)
$$

\section{Discussion}

\section{Spawning Tactics}

The abundant occurrences of Japanese Spanish mackerel eggs and larvae were restricted in a short period, late May to early June, in the central waters of the Seto Inland Sea. Previous works ${ }^{16,20)}$ reported that this species rarely spawned in July in this area even when the stock size was large. The restriction in time of egg and larval occurrence suggests that spawning period of Japanese Spanish mackerel is relatively short compared with the other species of Scomberomorus. ${ }^{24)}$ Scomberomorus sierra spawns almost all year long in the Panama Bight and it's spawning is characterized by a "bet-hedging" strategy during the nonupwelling period and by an "all-at-once" strategy during the upwelling period when plankton densities are high. ${ }^{25,26)}$ These differentiated spawning seasons seem to reflect the differences in reproductive strategy which adapt to seasonal or local food abundance. In the Seto Inland Sea, seasonal changes in abundance of ichthyoplankton are distinctive. ${ }^{27}$ It is reasonable to speculate that Japanese Spanish mackerel would have evolved an "all-at-once" reproductive strategy in which the spawning coincides with peak abundance of their ichthyoplankton prey.

\section{Prey Preference}

The present study demonstrated that Japanese Spanish mackerel larvae predominantly preyed on Clupeiformes larvae despite the presence of a variety of fish larvae in water. Nearly the same result was obtained for the Japanese Spanish mackerel larvae collected in early eighties, although the main species eaten then was Japanese anchovy larvae. ${ }^{21)}$ As shown in Fig. 4, most of the Japanese Spanish mackerel larvae had prey of less than 0.3 in BH:MD ratio in their stomachs. Although there is no com- parable data on $\mathrm{BH}: \mathrm{MD}$ ratio of prey ingested by marine fish larvae, the optimum prey size relative to mouth size was found to be 0.5 to 0.6 regardless of fish size in bluegill sunfish Lepomis macrochirus, green sunfish $L$. cyanellus, and a stickleback Spinachia spinachia. ${ }^{28,29)}$ The lower value of BH:MD ratio found in Japanese Spanish mackerel larvae would be related to undeveloped catchability primarily due to the low swimming performance. A preference of Japanese Spanish mackerel larvae for Clupeiformes larvae such as anchovy, sardine, and gizzard shad could be explained by the swimming ability of the larvae with slender body forms relative to larvae with a more robust form. ${ }^{2}$ This food preference should be tested ecologically using more detailed field data and behaviorally using laboratory experiments.

\section{Growth}

Based on age estimates from otolith increment counts, wild Japanese Spanish mackerel grew to about $10 \mathrm{~mm}$ SL in 10 days and $20 \mathrm{~mm} \mathrm{SL}$ in 20 days after hatching (Fig. 7). The relationships between SL and age in days for larvae and early juveniles of other Scomberomorus, $S$. cavalla from the Gulf of Mexico and $S$. maculatus from the U.S. South Atlantic Bight, were expressed by $S L=1.31 \cdot$ age -1.30 and $S L=0.82 \cdot$ age +0.37 , respectively. ${ }^{5)}$ The larval and juvenile growth rates in these three Scomberomorus were higher than other scombrids such as Atlantic mackerel Scomber scombrus, ${ }^{30}$ ) southern bluefin tuna Thunnus maccoyii, ${ }^{31)}$ bluefin tuna Thunnus thynnus, ${ }^{32)}$ and yellowfin tuna Thunnus albacares. ${ }^{33)}$

Compared to the larval and juvenile growth rate of the wild Scomberomorus obtained in the present study, a much larger growth rate in the same species was obtained in a rearing condition: reaching $18 \mathrm{~mm}$ TL in 10 days after hatching and $90 \mathrm{~mm}$ TL in a month. ${ }^{4)} \mathrm{A}$ similar phenomenon also occurred in yellowtail Seriola quinqueradiata, ${ }^{34)}$ suggesting a considerably faster growth in natural condition if a suitable growing condition is available. Food availability is expected to vary in the sea by year, which might bring about a considerable interannual variation in growth rate in Japanese Spanish mackerel larvae. The relationship between growth rate and survival and its temporal variation may be indispensable in understanding the recruitment mechanism of this species.

Acknowledgments The authors are grateful to Mr. Y. Ito, Mr. Y. Oiwa, Mr. T. Tanigawa, Mr. N. Murata, Mr. M. Ehara, and Mr. T. Maki, Toyo Branch, Ehime Prefecture Chuyo Fisheries Experimental Station, and Mr. K. Kamioka, Mr. K. Shiota, Mr. Y. Nishiyama, and Miss M. Kurono, Ehime Prefecture Chuyo Fisheries Experimental Station for their assistance in ichthyoplankton sampling, and to the members of $A s a-$ gi-suisan Corp. and Fijita-suisan Corp., Saijo, Ehime and Mekatsu-suisan Corp., Kan-onji, Kagawa for their kind help in collecting wild specimens with boat seine fishery. Thanks are due to Dr. J. S. Burke, NMFS Beaufort Laboratory, for his critical review of the manuscript and Mrs. Y. Nakamura, Faculty of Agriculture, Kyoto University for providing the reared specimens. This study was partly supported by the Fellowships of the Japan Society for the Promotion of Science for Japanese Junior Scientists.

\section{References}

1) J. R. Hunter and C. A. Kimbrell: Early life history of Pacific mackerel, Scomber japonicus. Fish. Bull, , 78, 89-101 (1980). 
2) J. R. Hunter: Feeding ecology and predation of marine fish larvae, in "Marine fish larvae" (ed. by R. Lasker), Univ. Washington Press, Seattle, 1981, pp. 33-77.

3) M. Higuchi and Y. Oshima: A prospect for seedling release of Spanish mackerel in the Seto Inland Sea. Saibai-giken, 3, 43-60 (1974) (in Japanese).

4) T. Fukunaga, N. Ishibashi, and N. Mitsuhashi: Artificial fertilization and seedling propagation of Spanish mackerel. Saibai-giken, 11, 29-48 (1982) (in Japanese).

5) D. A. DeVries, C. B. Grimes, K. L. Lang, and D. B. White: Age and growth of king and Spanish mackerel larvae and juveniles from the Gulf of Mexico and U. S. South Atlantic Bight. Env. Biol. Fish., 29, 135-143 (1990).

6) M. R. Collins, D. J. Schmidt, C. W. Waltz, and J. L. Pickney: Age and growth of king mackerel, Scomberomorts cavalla, from the Atlantic coast of the United States. Fish. Bull., 87, 49-61 (1988).

7) J. S. Peters and D. J. Schmidt: Daily age and growth of larval and early juvenile Spanish mackerel, Scomberomorus maculatus, from the South Atlantic Bight. Fish. Bull., 95, 530-539 (1997).

8) M. Tanaka, T. Kaji, Y. Nakamura, and Y. Takahashi: Developmental strategy of scombrid larvae: High growth potential related to food habits and precocious digestive system development, in "Survival strategies in early life stages of marine resources" (ed. by $Y$. Watanabe, Y. Yamashita, and Y. Oozeki), A. A. Balkema, Rotterdam, 1996, pp. 125-139.

9) G. P. Jenkins, N. E. Milward, and R. F. Hartwick: Food of larvae of Spanish mackerels, genus Scomberomorus (Teleostei; Scombridae), in shelf waters of the Great Barrier Reef. Aust. J. Mar. Freshw. Res., 35, 477-482 (1984).

10) S. P. Naughton and C. H. Saloman: Stomach contents of juveniles of king mackerel (Scomberomorus cavalla) and Spanish mackerel (S. maculatus), Northeast Gulf Sci., 5, 71-74 (1981).

11) J. H. Finucane, C. B. Grimes, and S. P. Naughton: Diets of young king and Spanish mackerel off the southeast United States. Northeast Gulf Sci., 11, 145-153 (1990).

12) T. Hamada and S. Iwai: Biological studies on sawara resources in Harima-nada and adjacent waters-I. On some morphological characters and growth. Nippon Suisan Gakkaishi, 33, 1013-1019 (1967).

13) T. Kishida, K. Ueda, and K. Takao: Age and growth of Japanese Spanish mackerel in the central and western waters of the Seto Inland Sea. Nippon Suisan Gakkaishi, 51, 529-537 (1985).

14) T. Kishida: Feeding habits of Japanese Spanish mackerel in the central and western waters of the Seto Inland Sea. Bull. Nansei Reg. Fish. Res. Lab., 20, 73-89 (1986).

15) T. Kishida: Distribution and migration of Japanese Spanish mackerel based on the catch and effort data in the central and western waters of the Seto Inland Sea. Bull. Nansei Reg. Fish. Res. Lab., 22, 13-27 (1989) (in Japanese).

16) T. Kishida and K. Aida: Maturation and spawning of Japanese Spanish mackerel in the central and western waters of the Seto Inland Sea. Nippon Suisan Gakkaishi, 55, 2065-2074 (1989).

17) T. Kishida: Relationship between growth and population density of Japanese Spanish mackerel in the central and western waters of the Seto Inland Sea. Bull. Nanset Reg. Fish. Res. Lab., 23, 35-41
(1990) (in Japanese).

18) M. Shinohara: Spawning and maturity of female Japanese Spanish mackerel Scomberomorus niphonius in the eastern Seto Inland Sea. Bull. Okayama Pref. Fish. Exp. Sta., 6, 28-34 (1991) (in Japanese).

19) K. Yokogawa: Changes in ovarian egg number and egg diameter composition in Spanish mackerel Scomberomorus niphonius during the spawning season. Nippon Suisan Gakkaishi, 61, 689-694 (1995) (in Japanese).

20) T. Kishida: Vertical and horizontal distribution of eggs and larvae of Japanese Spanish mackerel in the central waters of the Seto Inland Sea. Nippon Suisan Gakkaishi, 54, 1-8 (1988).

21) J. Shoji, T. Kishida, and M. Tanaka: Piscivorous habits of Spanish mackerel larvae in the Seto Inland Sea. Fisheries Sci., 63, 388-392 (1997).

22) T. Kishida: Fluctuations in year-class strength of Japanese Spanish mackerel in the central Seto Inland Sea. Nippon Suisan Gakkaishi, 57, 1103-1109 (1991).

23) A. Shirota: Studies on the mouth size of fish larvae. Nippon Suisan Gakkaishi, 36, 353-368 (1970).

24) B. B. Collette and C. E. Nauen: Scombrids of the world. FAO species catalogue vol. 2, 1983, pp. 59-79.

25) R. R. Lauth and R. J. Olson: Distribution and abundance of larval Scombridae in relation to the physical environment in the northwestern Panama Bight. Inter-Amer. Trop. Tuna Comm. Bull., 21, 127-167 (1996).

26) T. C. Lambert and D. M. Ware: Reproductive strategies of demersal and pelagic spawning fish. Can. J. Fish. Aquat. Sci., 41, 15651569 (1984).

27) T. Senta: Study on the distribution of eggs and larvae of fishes in the adjacent waters to western Japan. Special Rep. Okayama Pref. Fish. Exp. Sta., 1-80 (1964) (in Japanese).

28) E. E. Werner: The fish size, prey size, handling time relation in several sunfishes and some implications. J. Fish. Res. Board Can., 31, 1531-1536 (1974).

29) M. Kislalioglu and R. N. Gibson: Prey "handling time"' and its importance in food selection by the 15-spined stickleback, Spinachia spinachia (L.). J. Exp. Mar. Biol. Ecol., 25, 151-158 (1976).

30) A. W. Kendall and D. Gordon: Growth rate of Atlantic mackerel (Scomber scombrus) larvae in the Middle Atlantic Bight. Rapp. P.v. Réun. Cons. int. Explor. Mer, 178, 337-341 (1981).

31) G. P. Jenkins and T. L. O. Davis: Age, growth rate, and growth trajectory determined from otolith microstructure of southern bluefin tuna Thunnus maccoyil larvae. Mar. Ecol. Prog. Ser., 63, 93-104 (1990).

32) G. P. Scott, S. C. Turner, C. B. Grimes, W. J. Richards, and E. D. Brothers: Indices of larval bluefin tuna, Thunnus thynnus, abundance in the Gulf of Mexico; modeling variability in growth, mortality, and gear selectivity. Bull. Mar. Sci., 53, 912-929 (1993).

33) K. L. Lang, C. B. Grimes, and R. F. Shaw: Variations in the age and growth of yellowfin tuna larvae, Thunnus albacares, collected about the Mississippi River plume. Env. Biol. Fish., 39, 259-270 (1994).

34) Y. Sakakura and K. Tsukamoto: Age composition in the schools of juvenile yellowtail Seriola quinqueradiata associated with drifting seaweeds in the East China Sea. Fisheries Sci., 63, 37-41 (1997). 